1 Socio-economic inequities impact on tuberculosis in a

2 Southern European city: does the recession influence?

3 Authors: Albert Prats-Uribe ${ }^{1,2 *}$, Angels Orcau ${ }^{1,3}$, Joan Pau Millet ${ }^{1,3}$, Joan A. Caylà ${ }^{1,4}$

4 1. Epidemiology Service. Agència de Salut Pública de Barcelona, Barcelona

5 2. Unitat Docent de Medicina Preventiva i Salut Pública PSMar-UPF-ASPB

6 3. CIBER Epidemiología y Salud Pública (CIBERESP), Madrid, Spain.

7 4. Foundation of Tuberculosis Research Unit of Barcelona

8

$9 \quad *$ Corresponding autor:

10 Albert Prats Uribe

11 E-mail: albert.pratsu@gmail.com

12 Agència de Salut Pública de Barcelona

13 Pl. de Lesseps, 1, 08023 Barcelona Spain

14

15 Running head

Impact of inequities and recession on TB

\title{
17 Counts
}

word count of the summary: 200

word count of the text: 2456

20

number of references: 23

21

Tables 3

22 Figures 2 


\section{Summary}

26

27

Introduction: Economic crises affect the population's health, especially among the most deprived. The increase in health inequalities in this recession may have influenced the incidence of tuberculosis (TB). We analyzed the effect of socioeconomic inequities and the recession on the incidence of TB.

Methods: We conducted a population-based incidence study of TB cases in Barcelona, Spain, who started treatment between 2003 and 2015. A multilevel interrupted time series analysis was done to analyze differences in incidence trends between the pre-recession (until 2008) and recession periods.

Results: We observed differences in TB incidence according to deprivation and immigration status. TB incidence among most deprived neighborhoods was 2.72 times higher than least deprived. Compared to natives, incidence was 9 times higher among those born in Africa, and 6 times higher among those born in Asia and Oceania. The previous decreasing trend in incidence (4\%) was accentuated during the recession (7\%).

Conclusions: The incidence of TB decreased during the recession, probably due to a reduction of new immigrants and the TB programme. However, incidence is highly unequal between districts with different levels of deprivation, and between foreign-born from different geographical regions. Social measures are important for reducing inequalities and TB incidence in Barcelona.

\section{Keywords:}

Economic Recession, Health Equity, Poverty, Socioeconomic status, Transients and Migrants, Tuberculosis (TB) 
48

49

\section{Introduction}

Tuberculosis (TB) is still a widespread disease, with high morbidity and mortality, even higher than HIV $^{1}$, especially among socio-economically disadvantaged groups.

Approximately $50 \%$ of the variation in TB incidence is due to level of wealth, and especially to the heterogeneous distribution of wealth, with a greater effect on foreign-born from countries with low income and high incidence ${ }^{2,3}$.

Previous studies have examined the impact of past recessions on health, and the effect have been found to differ. For example, a study of the Great Depression of 1929 observed a decrease in infectious disease mortality ${ }^{4}$. In contrast, in the recession following the collapse of the Soviet Union, there was an increase in the number of TB cases and TB-related deaths in the region, where it had previously been in decline, and an increase in the number of multidrug-resistant strains ${ }^{5}$.

A systematic review of studies on communicable diseases in 27 countries going through an economic recession showed that most had poorer results for infectious diseases, and concluded that the incidence of infectious diseases depended heavily on levels of social investment by the government ${ }^{6}$. Additionally, factors associated with low socioeconomic status, such as tobacco or alcohol consumption, overcrowding, and malnutrition, have been clearly associated with the spread and progression of TB ${ }^{7}$. Barcelona (BCN) is a low incidence TB setting (17 cases per 100,000), and this incidence has been decreasing from 2000 , at a $3.3 \%$ annual rate ${ }^{8}$. This city has a TB Prevention and Control Program's (PPCTB) that is well-established and has been carrying out contact studies and patient follow-up, and has been directly observing treatment in cases of possible adherence problems. It also has a team of public health nurses and community health workers who act as translators, mediators, and facilitators between the patient and health care system and improve contact tracing among the foreign-born population ${ }^{9,10}$.

In this context, the current economic recession, which impacted Spain enormously with a mean yearly drop in GDP of 2\% through the period a 2.5 rise of unemployment from 2008 to 2015 of 9.6\% to $23.8 \%,{ }^{11}$ government cutbacks have had an impact on Barcelona's wealth as a city and on the living conditions of its inhabitants, especially among the most disadvantages groups, such as foreignborn ${ }^{12}$.

While some authors have warned of the effects of the current economic recession on TB prevention and control measures ${ }^{13}$, it is not yet clear what impact these measures may have had on the incidence of this disease, mainly on those groups of population more vulnerable to decrease of 
81 public investment. Therefore, in this study we analyze the effects of social inequalities and economic 82 recession on TB incidence in this mediterranean city for 13 years. Our analyses explore incidence 83 distribution differences between the Spanish-born and foreign-born populations, and consider the 84 subjects' country of origin and sex, and the socioeconomic status of the neighborhood where they 85 live. 
87

\section{Design and study population}

We conducted an ecological study of annual incidence, using neighborhoods as the unit of analysis. The population under study were all residents in the city of Barcelona (average population of 1.6 million inhabitants) ${ }^{14}$. We studied all TB cases detected by the Barcelona Public Health Agency's Epidemiology Service through the PPCTB active surveillance system, and that were included in the Notifiable Diseases Surveillance System between 2003 and 2015.

\section{Sources of information}

We collected the individual variables from the TB epidemiological questionnaire completed by the PPCTB's nursing team in collaboration with the doctor who diagnosed and monitored the patient. The survey includes sociodemographic, clinical, and follow-up variables until completion of treatment.

From the city population register, we obtained the year to year population (on January 1 ) for each of the city's neighborhoods, and for each age group, sex, and region of origin ${ }^{14}$.

\section{Variables}

The dependent variable in this study was the year to year TB incidence, calculated dividing the number of reported cases of TB by the annual population of each group studied.

The main independent variables were: sex, age, year, country of birth, and region of origin. We coded the 'region of origin' variable according to birth country: Spain, EU-15, other European countries, other developed countries, Asia and Oceania, the Maghreb, other African countries, and Central and South America.

The neighborhood where each subject resided was determined from the address and was categorized according to the index of disposable household income (DHI) at the beginning of the recession: very high (>159), high (126-159), middle (100-125), middle-low (79-99) and low (<79). The $\mathrm{DHI}$ is strongly correlated with health inequities, and was designed by the city's Department of Statistics ${ }^{15}$.

We used the 'year treatment started' variable to create a recession variable with two values: prerecession period, from 2003-2008, and recession period, from 2009-2015. We chose 2008 as the cut- 
off point because that year is considered to be the start of the global economic recession; Spain entered into a recession during the first quarter of 2009.

\section{Statistical methods}

We calculated the annual incidence in cases per 100,000 inhabitants for the entire city and the specific incidences according to sex, immigration status, region of origin, $\mathrm{DHI}$, and year.

We constructed various random-effects models for repeated data by fitting the dependent variable (incidence) on a negative binomial distribution, and used these models to estimate TB incidence rates (IR) and 95\% confidence intervals ( $\mathrm{Cl}$ ). We added, as in an interrupted time series model, a recession dummy, to account for a step change ( $\Delta$ incidence rate/1000 personyears (py)), the immediate change in incidence level after the recession start and a recession trend, to account for the slope, or annual change ( $\Delta$ incidence rate/1000 py per each year) in incidence and use these parameters to evaluate whether the trend in incidence changed after the beginning of the recession. ${ }^{16}$

Model 1 included the variables recession, year, recession-year interaction, DHI, age group, migratory status, and sex. We repeated this model separately for men and women, and for foreign-born and Spanish-born.

Model 2 included the variables recession, year, recession-year interaction, DHI, sex, and region of origin. We repeated this model separately for men and women. All analyses were performed using the STATA statistical package, version 13.1 SE.

\section{Results}

Our study included a total of 4,656 cases of TB from Barcelona's 73 neighborhoods, with an average total population of 1,608,966 over the thirteen-year period between 2003 and 2015.

Most people in the city $(60 \%)$ lived in medium-low and low income neighborhoods. Foreign-born represented $19 \%$ of the total population in this period, most of whom were from Central and South America followed by Asia.

Table 1 shows the average annual incidences before and after the beginning of the recession. Both the number of cases and the average incidence in the city was lower during the recession period, in both men and women, across all age groups, and in both the native and foreign-born populations. 
Figures 1 and 2 show the incidence throughout the study period among foreign-born and Spanishborn, respectively. Tables 2 and 3 show the results of the regression models. Overall, TB incidence decreased by $4 \%$ per year ( $\mathrm{Cl}: 6-1 \%)$, after controlling for the other variables, mainly driven by the native population, in whom incidence decreased by $5 \%$. (Cl: $8-3 \%)$. In the foreign-born population incidence remained stable before the recession.

The global incidence trend appears to have decreased even further during the recession, as we can see in the interaction between previous trend and the slope change, by $3 \%(\mathrm{Cl}: 6-1 \%)$ mainly in the foreign-born population, in whom the incidence had decreased by $7 \%$ (CI: 11-2\%) from the start of the recession, thought it was higher at the beginning of the period (41\%; $\mathrm{Cl}: 7-86 \%)$. We found that the trend among the native population was not altered by the onset of the recession.

In terms of the income level for neighborhoods where the cases were resident, the incidence was markedly higher in neighborhoods with lower income, especially in the foreign-born population (3.57 (Cl: 2.60-4.91) times greater in low-income than high-income neighborhoods).

There was also a difference in the age-related distribution of TB incidence between Spanish-born and foreign-born populations. Among natives, TB risk was highest among over 75-years-olds, whereas among foreign-born, risk was higher among 15-29-year-olds.

The results for model 2 (Table 3) were very similar to those for model 1 in terms of trends and the effect of the economic recession. There were clear differences in incidence according to country of origin, with individuals from Asian countries and those from Africa showing 6.13 (Cl: 5.35-7.02) and 8.90 (Cl: 7.19-11.03) times greater incidence than natives, respectively. Residents born in EU-15 countries showed lower incidence (0.64; $\mathrm{Cl}$ : 0.49-0.85).

\section{Discussion}

In this study we observed a clear decreasing trend in TB incidence over time in the native population, and that this trend was unchanged during the period of economic recession (2009-2015). In the foreign-born population, incidence slowly decreased but remained higher than in Spanish-born population, as has been seen in other similar settings. ${ }^{17}$ After the start of the recession, there was a downward trend in incidence. TB incidence differed markedly between Barcelona's neighborhoods according to income, with a clear tendency for wealthier districts to have lower TB incidence than more disadvantaged areas. This inequality was much more pronounced in the foreign-born 
community, where we observed higher incidences, with foreign-born residents from sub-Saharan Africa and Asia, having the highest incidences: 6-9 times greater incidence than the native population. This is fully consistent and mirrors the global TB burden ${ }^{1}$, with high TB rates in subSaharan Africa and in Pakistan and Meridional Asia, where most of the Asian Barcelona citizens come from. ${ }^{14}$

During recession the trend of declining TB rates in recent years appears to have been reinforced due to its impact on the foreign-born population, which could be explained by several processes. One factor could be the notable decrease in the immigration rate, which was negative during some years of the recession period, with a mean $1 \%$ yearly decrease, ${ }^{18}$ and the fact that TB generally manifests itself in migrant workers shortly after they arrive to the host country ${ }^{19}$. Another factor could be that government austerity measures did not markedly affect the care of TB patients, even though they had negative consequences for the health system in general. Despite Royal Decree-Law 16/2012, which limits public health care for non-legal residents in Spain, Catalonia and other autonomous communities have continued to provide basic health care to undocumented immigrants, especially for patients suffering infectious diseases, by providing health cards and facilitating access to care. Maintaining an effective TB control program in the city could have contributed to disease control even in poorer economic conditions.

Neighborhood income level is one of the factors that best explains TB incidence, and this inequality in TB incidence does not appear to have changed during the recession. In the native population, the general tendency is for absolute inequality between districts to be reduced, although the relative inequalities remain the same, especially between the richest and the poorest neighborhoods. In this context, social protection measures as well as health measures could be important in reducing incidence ${ }^{20}$. The effect neighborhood income level is an even greater determinant of TB incidence among foreign-born population.

Studying foreign-born population as a single group creates an important generalization error, as there are notable differences in the cultural and ethnic characteristics and health experiences between subgroups ${ }^{21}$. Thus, we studied foreign-born according to region of origin, with a level of disaggregation that allowed us to retain sufficient statistical power. We observed considerable inequality in TB incidence according to region of origin, which makes incidence in this group also highly dependent on country of origin ${ }^{22}$, as well as on the socioeconomic level of the neighborhood where they live. This inequality persists even though the city has an effective TB program, and even after the decrease in immigration, indicating that the high incidence in this group is not only due to immigrants arriving when they are already infected and developing the disease post-migration. The 
living and socioeconomic conditions of residents born in countries with a high TB burden may perpetuate these high incidences once they are settled in the city. The high incidences in foreignborn, especially in the younger, could precipitate the introduction of specific public health measures such as opportunistic detection of infections, especially for identifying patients, and taking advantage of the health systems' contact with individuals from countries with a high disease burden ${ }^{23}$.

An strenght of this study was the extensive nature of the registry we used and the quality of data collected from the PPCTB, providing us with realistic estimates of incidence and reliable data on residence neighborhood and country of origin, which could be difficult to collect in other contexts. Also, including data from the population register on all residents in Barcelona allowed us to study incidence trends in this large city. Furthermore, the ability to analyze different subgroups (neighborhood, sex, country of origin) allowed us to evaluate inequalities between these groups within the territory.

One of our study's limitation was that the income level of each neighborhood was considered to remain unchanged over time due to lack of information from 2005-2007. However, when comparing the DHI for 2004 to that for 2008 and later, for which information was available, we found that none of the neighborhoods changed category. Data from the population register do not reflect the homeless population, who represent $7.8 \%$ of TB cases during the study period, so it would be interesting to study in greater detail the effect of the recession on TB incidence in this group. Another limitation of the study was the design itself, which, as an ecological study, precludes causal inference at the individual level.

Studying only the city of Barcelona could be considered as a limitation of the external validity of our results. However, the strength of a population-based study such as ours enables us, in principle, to extrapolate the results to other large cities with a similar profile, population characteristics, tuberculosis rates and control measures to those of Barcelona.

\section{Conclusions}

During the recent economic recession, the previous decreasing trend in TB incidence in the city of Barcelona was accentuated. The incidence decreased especially among the natives but also among the foreign born. However, there are significant inequalities between neighborhoods according to the average income level and also to residents' country of birth. This study confirms that TB continues to be a social disease. Thus, it is important to implement policies to control social determinants and to reduce these inequalities, both locally and globally, as well as maintain and reinforce TB control programs. 
238 Funding and conflicts of interest

239 Funded by the 'Fondo de Investigación en Salud' [grant number FIS 2015 PI13 (02757) ] project. 


\section{References}

2421 World Health Organization. WHO Global tuberculosis report 2017. 2017 DOI:ISBN 978924

$243 \quad 1565394$.

2 Ploubidis GB, Palmer MJ, Blackmore C, et al. Social determinants of tuberculosis in Europe: a prospective ecological study. Eur Respir J 2012; 40: 925-30.

Suk JE, Manissero D, Büscher G, Semenza JC. Wealth inequality and tuberculosis elimination in Europe. Emerg Infect Dis 2009; 15: 1812-4.

Tapia Granados JA, Diez Roux A V. Life and death during the Great Depression. Proc Natl Acad Sci U S A 2009; 106: 17290-5.

Arinaminpathy $\mathrm{N}$, Dye $\mathrm{C}$. Health in financial crises: economic recession and tuberculosis in Central and Eastern Europe. J R Soc Interface 2010; 7: 1559-69.

Suhrcke M, Stuckler D, Suk JE, et al. The impact of economic crises on communicable disease transmission and control: a systematic review of the evidence. PLoS One 2011; 6: e20724.

Lönnroth K, Jaramillo E, Williams BG, Dye C, Raviglione M. Drivers of tuberculosis epidemics: The role of risk factors and social determinants. Soc Sci Med 2009; 68: 2240-6.

Orcau A, Arcas M, Caylà JA, García de Olalla P. La tuberculosi a Barcelona. Informe 2013. 2015; $: 65$.

Caylà JA, Orcau A. Control of tuberculosis in large cities in developed countries: an organizational problem. BMC Med 2011; 9: 127.

Ospina JE, Orcau A, Millet J-P, Sánchez F, Casals M, Caylà JA. Community health workers improve contact tracing among immigrants with tuberculosis in Barcelona. BMC Public Health 2012; 12: 158.

INE España. Instituto Nacional de Estadística. Minist. Econ. Ind. y Compet. 2017.

Catalunya $\mathrm{O}$ del $\mathrm{S}$ de $\mathrm{S}$ de. Efectes de la crisi econòmica en la salut de la població de Catalunya. Anàlisi territorial. Barcelona, 2015 http://observatorisalut.gencat.cat/web/.content/minisite/observatorisalut/ossc_crisi_salut/Fi txers_crisi/Salut_crisi_informe_2015.pdf (accessed April 29, 2016).

Odone A, Signorelli C, Rodrigues LC. Tuberculosis and the economic crisis: an old threat for the new European agenda. Scand J Public Health 2014; 42: 834-5.

Ajuntament de Barcelona. Departament d'estadística. 2014; published online Jan 15. http://www.bcn.cat/estadistica/catala/ (accessed Nov 25, 2014).

Martí C, Casas E, Juan AJ, et al. Distribució territorial de la Renda Familiar per càpita a Barcelona. http://www.bcn.cat/publicacions/pdf/rfd.pdf (accessed Nov 25, 2014).

Wagner AK, Soumerai SB, Zhang F, Ross-Degnan D. Segmented regression analysis of interrupted time series studies in medication use research. J Clin Pharm Ther 2002; 27: 299309.

Odone A, Riccò M, Morandi M, Borrini BM, Pasquarella C, Signorelli C. Epidemiology of tuberculosis in a low-incidence Italian region with high immigration rates: differences between not Italy-born and Italy-born TB cases. BMC Public Health 2011; 11: 376. 
Barcelona. 2016 www.bcn.cat/estadistica (accessed May 31, 2018).

19 Chan IHY, Kaushik N, Dobler CC. Post-migration follow-up of migrants identified to be at increased risk of developing tuberculosis at pre-migration screening: a systematic review and meta-analysis. Lancet Infect Dis 2017; 17: 770-9.

20 Siroka A, Ponce NA, Lönnroth K. Association between spending on social protection and tuberculosis burden: a global analysis. Lancet Infect Dis 2016; 16: 473-9.

21 Villarroel N, Artazcoz L. Heterogeneous patterns of health status among immigrants in Spain. Health Place 2012; 18: 1282-91.

22 Ködmön C, Zucs P, van der Werf MJ. Migration-related tuberculosis: epidemiology and characteristics of tuberculosis cases originating outside the European Union and European Economic Area, 2007 to 2013. Euro Surveill Bull Eur sur les Mal Transm = Eur Commun Dis Bull 2016; 21. DOI:10.2807/1560-7917.ES.2016.21.12.30164.

23 Panchal RK, Browne I, Monk P, Woltmann G, Haldar P. The effectiveness of primary care based risk stratification for targeted latent tuberculosis infection screening in recent immigrants to the UK: a retrospective cohort study. Thorax 2014; 69: 354-62.

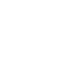


317 Table 1: Population, cases, and incidence (cases/100,000 population) according to income level, 318 sex, and immigration status (before and after the recession and throughout the study period).

319 Barcelona, 2003-2015.

\begin{tabular}{|c|c|c|c|c|c|c|c|}
\hline & \multirow[b]{2}{*}{$\begin{array}{c}\text { Average } \\
\text { annual } \\
\text { population }\end{array}$} & \multicolumn{2}{|c|}{$\begin{array}{l}\text { Pre-recession period } \\
\text { 2003-2008 }\end{array}$} & \multicolumn{2}{|c|}{$\begin{array}{c}\text { Recession period } \\
2009-2015\end{array}$} & \multicolumn{2}{|c|}{$\begin{array}{c}\text { Overall } \\
2003-2015\end{array}$} \\
\hline & & Cases & $\begin{array}{l}\text { Average } \\
\text { annual } \\
\text { incidence }\end{array}$ & Cases & $\begin{array}{l}\text { Average } \\
\text { annual } \\
\text { incidence }\end{array}$ & $\begin{array}{l}\text { Total } \\
\text { cases }\end{array}$ & $\begin{array}{c}\text { Average } \\
\text { annual } \\
\text { incidence }\end{array}$ \\
\hline Barcelona & 1608966 & 2677 & 27.9 & 2428 & 21.4 & 4656 & 22.3 \\
\hline \multicolumn{8}{|l|}{ Disposable household income } \\
\hline Very high & 126026 & 92 & 12.4 & 92 & 10.3 & 164 & 10.0 \\
\hline High & 151722 & 157 & 17.4 & 132 & 12.4 & 260 & 13.2 \\
\hline Middle & 369830 & 509 & 23.2 & 418 & 16.0 & 832 & 17.3 \\
\hline Middle- low & 579922 & 904 & 26 & 797 & 19.6 & 1506 & 20.0 \\
\hline Low & 381835 & 1015 & 44.7 & 989 & 36.7 & 1776 & 35.8 \\
\hline \multicolumn{8}{|l|}{ Sex } \\
\hline Men & 763262 & 1666 & 36.6 & 1471 & 27.4 & 2891 & 29.1 \\
\hline Women & 846074 & 1011 & 20.0 & 957 & 16.1 & 1765 & 16.0 \\
\hline \multicolumn{8}{|l|}{ Country of origin } \\
\hline Spanish-born & 1298101 & 1580 & 19.7 & 1175 & 13.3 & 2461 & 14.6 \\
\hline Foreign-born & 311235 & 1097 & 69.5 & 1253 & 50.8 & 2077 & 51.3 \\
\hline \multicolumn{8}{|l|}{ Age group (years) } \\
\hline 0 to 14 & 193792 & 159 & 14.2 & 123 & 8.8 & 282 & 11.2 \\
\hline 15 to 29 & 278012 & 629 & 35.1 & 515 & 28.3 & 1144 & 31.7 \\
\hline 30 to 44 & 399496 & 873 & 37.3 & 821 & 28.8 & 1694 & 32.6 \\
\hline 45 to 64 & 402210 & 513 & 21.8 & 530 & 18.4 & 1043 & 19.9 \\
\hline 65 to 74 & 158084 & 217 & 22.3 & 187 & 17.3 & 404 & 19.7 \\
\hline older than 75 & 177742 & 286 & 28.2 & 252 & 19.4 & 538 & 23.3 \\
\hline \multicolumn{8}{|l|}{ Region of origin } \\
\hline Spain & 1298101 & 1580 & 19.7 & 1175 & 13.3 & 2461 & 14.6 \\
\hline EU-15 & 45843 & 36 & 16.8 & 21 & 5.6 & 50 & 8.4 \\
\hline Rest of Europe & 25671 & 59 & 67.2 & 100 & 46.9 & 170 & 50.9 \\
\hline Other developed countries & 6332 & 3 & 9.4 & 5 & 9.9 & 7 & 8.5 \\
\hline Asia & 50695 & 368 & 167.4 & 547 & 125.7 & 811 & 123.1 \\
\hline The Maghreb & 18273 & 89 & 94.6 & 94 & 72.5 & 183 & 77.0 \\
\hline Other African countries & 5757 & 51 & 184.2 & 68 & 149.3 & 104 & 139.0 \\
\hline Central and South America & 158660 & 491 & 58.6 & 418 & 34.4 & 843 & 40.9 \\
\hline
\end{tabular}



status. Barcelona, 2003-2015.

\begin{tabular}{|c|c|c|c|}
\hline Model Variable & Overall* & Spanish-born* & Foreign-born* \\
\hline Incidence trend + & $0.96(0.94-0.99)$ & $0.95(0.92-0.97)$ & $0.99(0.96-1.03)$ \\
\hline Recession step change + & $1.18(0.98-1.44)$ & $1.00(0.77-1.32)$ & $1.41(1.07-1.86)$ \\
\hline Recession slope change + & $0.97(0.94-0.99)$ & $0.99(0.95-1.04)$ & $0.93(0.89-0.98)$ \\
\hline Women & 1 & 1 & 1 \\
\hline Men & $1.65(1.52-1.78)$ & $1.80(1.63-1.99)$ & $1.43(1.28-1.60)$ \\
\hline High income & 1 & 1 & 1 \\
\hline Higher-middle- income & $1.27(1.01-1.58)$ & $1.21(0.92-1.59)$ & $1.39(0.95-2.04)$ \\
\hline Middle income & $1.63(1.35-1.96)$ & $1.50(1.19-1.90)$ & $1.88(1.35-2.61)$ \\
\hline Low income & $1.91(1.60-2.28)$ & $1.69(1.36-2.10)$ & $2.34(1.70-3.22)$ \\
\hline Very low income & $2.72(2.27-3.25)$ & $2.30(1.84-2.87)$ & $3.57(2.60-4.91)$ \\
\hline Spanish-born & 1 & - & - \\
\hline Foreign-born & $3.08(2.84-3.35)$ & - & - \\
\hline 0 to 14 years & 1 & 1 & 1 \\
\hline 15 to 29 years & $1.89(1.62-2.21)$ & $1.59(1.29-1.96)$ & $1.90(1.51-2.40)$ \\
\hline 30 to 44 years & $2.01(1.73-2.34)$ & $2.32(1.90-2.82)$ & $1.62(1.28-2.04)$ \\
\hline 45 to 64 years & $1.69(1.45-1.98)$ & $1.89(1.55-2.29)$ & $1.38(1.08-1.77)$ \\
\hline 65 to 74 years & $1.97(1.67-2.36)$ & $2.28(1.85-2.80)$ & $1.15(0.77-1.72)$ \\
\hline older than 75 & $2.67(2.25-3.16)$ & 3.17 (2.59-3.87) & $0.86(0.51-1.45)$ \\
\hline
\end{tabular}
precise moment at which the crisis started, Slope change denotes the added slope to the previous trend during the recession. 
358 Table 3: Incidence trends according to region of origin and income level. Barcelona, 2003-2015.

\begin{tabular}{|c|c|}
\hline Variables & Incidence rate * $(95 \% \mathrm{Cl})$ \\
\hline Incidence trend + & $0.97(0.95-0.99)$ \\
\hline Recession step change + & $1.21(0.99-1.48)$ \\
\hline Recession slope change + & $0.96(0.93-0.99)$ \\
\hline Women & 1 \\
\hline Men & $1.48(1.35-1.62)$ \\
\hline High income & 1 \\
\hline Higher-middle- income & $1.26(0.96-1.65)$ \\
\hline Middle income & $1.62(1.29-2.04)$ \\
\hline Low income & $1.85(1.49-2.30)$ \\
\hline Very low income & $2.43(1.95-3.02)$ \\
\hline Spanish-born & 1 \\
\hline EU-15 & $0.64(0.49-0.85)$ \\
\hline Rest of Europe & $2.86(2.37-3.46)$ \\
\hline Other developed countries & $0.74(0.37-1.49)$ \\
\hline Asia & $6.13(5.35-7.02)$ \\
\hline The Maghreb & $3.97(3.29-4.79)$ \\
\hline Other African countries & $8.90(7.19-11.03)$ \\
\hline Central and South America & $2.68(2.38-3.01)$ \\
\hline
\end{tabular}




\section{FIGURES}

377 Fig 1. Year-to-year incidence (cases per 100,000 population, axis in a log scale) of tuberculosis among foreign-born residents, according to socioeconomic status (disposable household income group). Barcelona, 2003-2015.

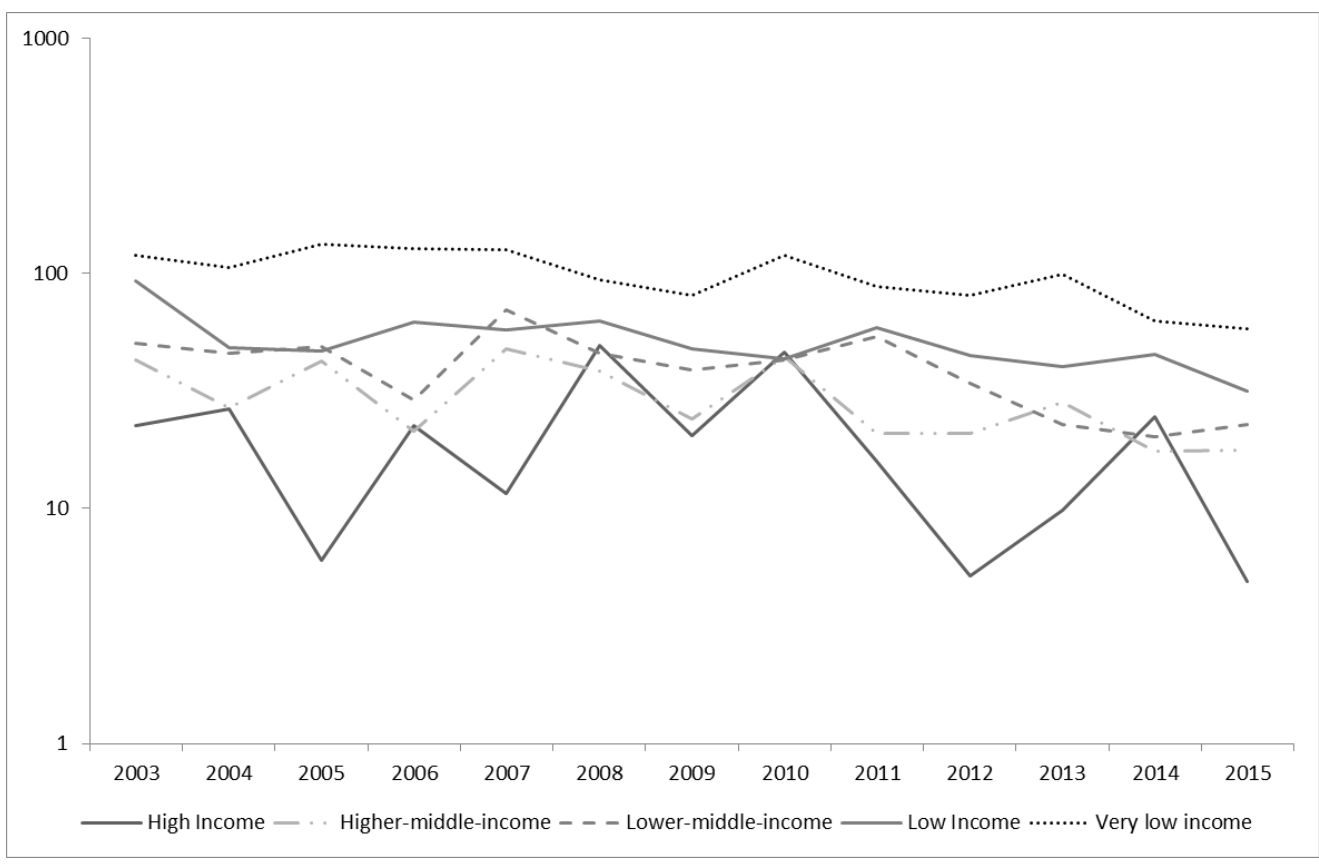

Fig 2. Year-to-year incidence (cases per 100,000 population, axis in a log scale) of tuberculosis among Spanish-born residents, according to socioeconomic status (disposable household income). Barcelona, 2003-2015.

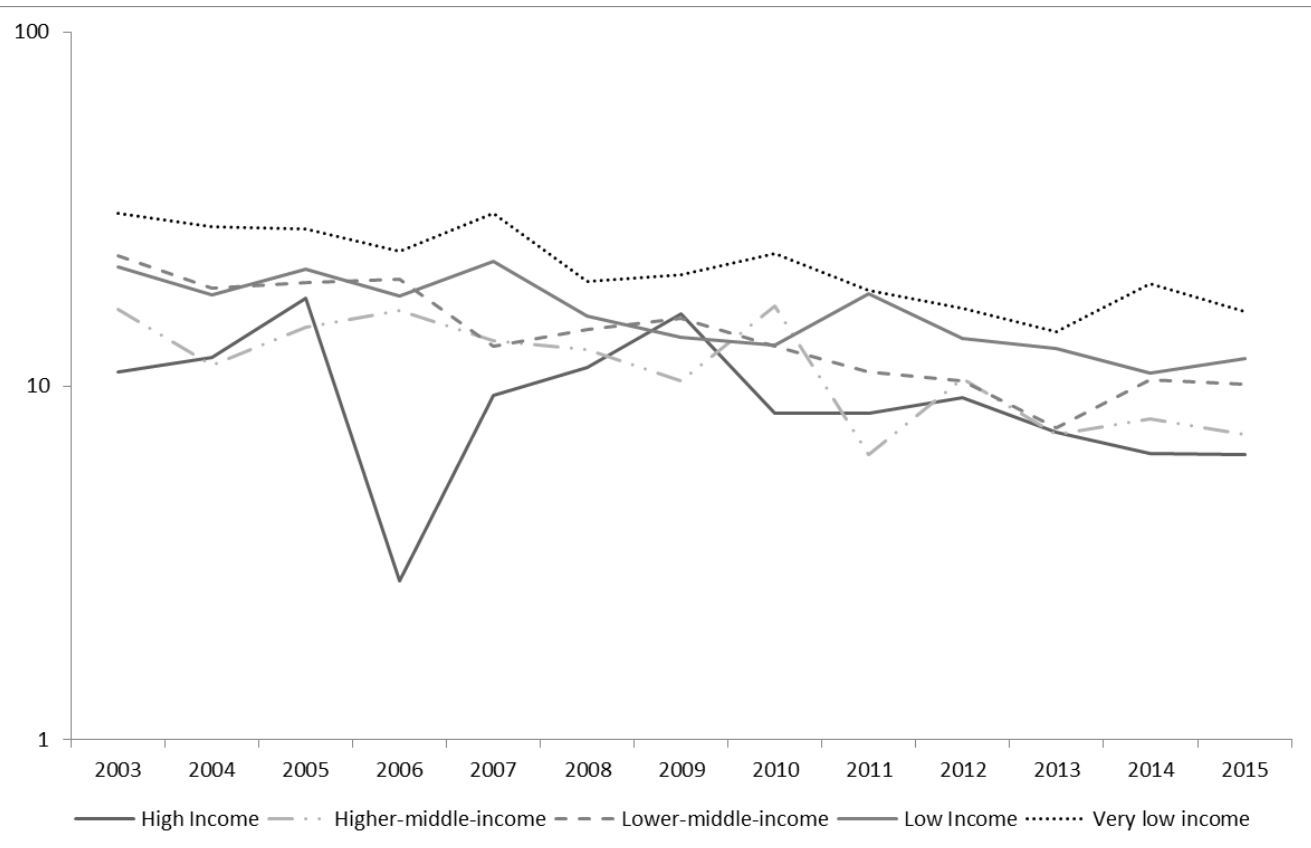

